\title{
The Time-Varying Characteristics of Overhead Electric Transmission Lines Considering the Induced-Ice-Shedding Effect
}

\author{
Kunpeng Ji, ${ }^{1}$ Xiaoming Rui, ${ }^{1}$ Lin Li, ${ }^{1}$ Chao Zhou, ${ }^{1}$ Chen Liu, ${ }^{1}$ and Ghyslaine McClure ${ }^{2}$ \\ ${ }^{1}$ School of Energy Power, Mechanical Engineering, North China Electric Power University, Beijing 102206, China \\ ${ }^{2}$ Department of Civil Engineering and Applied Mechanics, McGill University, Montreal, QC, Canada H3A 0C3 \\ Correspondence should be addressed to Kunpeng Ji; jkp2135@163.com
}

Received 18 May 2015; Accepted 2 July 2015

Academic Editor: Sundararajan Natarajan

Copyright (C) 2015 Kunpeng Ji et al. This is an open access article distributed under the Creative Commons Attribution License, which permits unrestricted use, distribution, and reproduction in any medium, provided the original work is properly cited.

More ice deposits accreted on conductors or ground wires may be shed off when an overhead electric transmission line is responding to shocks initiated by natural ice shedding. Ice shedding causes the global mass, stiffness, and damping of the tower-line system to vary with time, and the successive shedding effect beyond a trigger event has not been taken into account in previous studies due to the lack of an adequate ice detachment model. In this paper, the ice shedding effect induced by initial shocks was considered in finite element (FE) analysis. An ice detachment criterion, in the way of user-defined element rupture subroutine, was implemented into the main commercial nonlinear FE program ADINA, making it possible to consider the induced-ice-shedding effect numerically. The incremental FE form of the system's governing equations of motion is presented where the variations in the mass and stiffness matrices of the system are taken into consideration. Taking a transmission line section following natural ice shedding as a case study, the results indicate that neglecting successive ice shedding underestimates the adverse influence of natural ice shedding. The proposed method can help to improve the design and evaluation of transmission lines in cold regions and to ensure their mechanical security.

\section{Introduction}

Systems with time-varying mass, stiffness, and (or) damping occur frequently in mechanical and civil engineering practice $[1,2]$. Overhead electric transmission lines are one of the typical time-varying dynamic systems, for they are subjected to various environmental loads, such as wind, rain, snow, and ice. The time-varying characteristics of transmission lines during rain-wind induced vibrations have been the subject of several studies $[3,4]$, while their vibrations due to snow or ice shedding have not been addressed as much in open literature.

Ice shedding is the phenomenon by which ice deposits accreted on conductors or ground wires of transmission lines suddenly drop off under certain temperature and wind conditions [5-7] (natural ice shedding) or direct mechanical shock. The sudden detachment of ice may lead to severe vibrations of the cables and may cause both mechanical and electrical problems to transmission lines [5-7].

Morgan and Swift [5] were the first to study the jump height of suspended cables after ice shedding. With the development of finite element (FE) techniques, Jamaleddine et al. [6] were the first to use commercial nonlinear FE software (ADINA [8]) to study the dynamic response of transmission lines following ice shedding. The modeling methodology and numerical results were validated with experimental data. Following this work, Fekr and McClure [7] studied a total of 21 ice shedding numerical models, which led to a deeper understanding of ice shedding effects on line response. Kollár et al. [9] studied the effect of ice shedding propagation with various velocities in FE analysis and validated their FE model by the real-scale ice shedding tests conducted by Van Dyke and Laneville in [10]. Kollar and Farzaneh [11, 12] were also 
the first to simulate the sudden ice shedding from bundled conductors. Meng et al. [13] performed several real-scale ice shedding tests and then studied the influence of damping ratios and other factors. Yan et al. [14] proposed a formula to calculate the jump height of lines after ice shedding. Yang et al. [15] also put forward important suggestions for the design of ultra-high voltage transmission lines considering natural ice shedding.

In all of the above studies, ice shedding was assumed to occur either in an instant or in certain prescribed sequences, and when the prescribed ice shedding (referred to as "initial ice shedding" in this paper) was completed, it was assumed that no further ice was shed off during the subsequent transient vibration of the line. In other words, the mass of the dynamic system remains constant after the initial shedding has occurred, and the stiffness of the system may change but only stemming from material and (or) geometric nonlinearity. Besides, the ice shedding mechanism itself was not considered in those studies, either.

However, in reality, the ice still accreted on the lines after initial shedding may be shed off (referred to as "induced-iceshedding") due to the line vibration generated by the initial ice shedding and the insufficient adhesive force at the icecable interface and cohesive force within the ice deposits. As further ice shedding occurs, the mass, stiffness, and damping contributions of the detached ice are to be removed from the transmission line system matrices. In other words, the induced-ice-shedding effect, ignored in previous studies, causes the mass, stiffness, and damping of the dynamic system to vary with time during the vibration, which may further aggravate the conductor transient vibration. With the availability of proper modeling tools, it is now feasible to consider the induced-ice-shedding effect in dynamic analysis of natural ice shedding phenomenon.

In other similar studies, where the transmission line was impacted by mechanical deicing shocks, Kálmán et al. [16] proposed an ice failure criterion (the stress criterion) to consider the ice detachment mechanism in FE simulation, making it possible to simulate the ice shedding induced by impulse loads. Then, Mirshafiei et al. [17] improved the criterion to the total strain criterion and successfully applied it to dynamic analysis of transmission lines subjected to cable rupture shocks [18]. Recently, as an improvement, the authors $[19,20]$ proposed an ice detachment criterion which considered both the adhesive force at the ice-cable interface and the cohesive force within the ice to explain the ice detachment mechanism. By comparing numerical results with reduced-scale and real-scale mechanical deicing tests, it was shown that the ice detachment criterion combined with the stress/strain ice failure criterion provides much improved prediction of the dynamic response of the test lines than previous modelling methods [19]. In the present study, the ice detachment criterion is modified and implemented into a user-defined subroutine in FE analysis, allowing considering explicitly the induced-ice-shedding effect on transmission lines following initial natural ice shedding. The numerical results of a line section following ice shedding obtained by the proposed method are discussed and compared with the results obtained by previous methods.
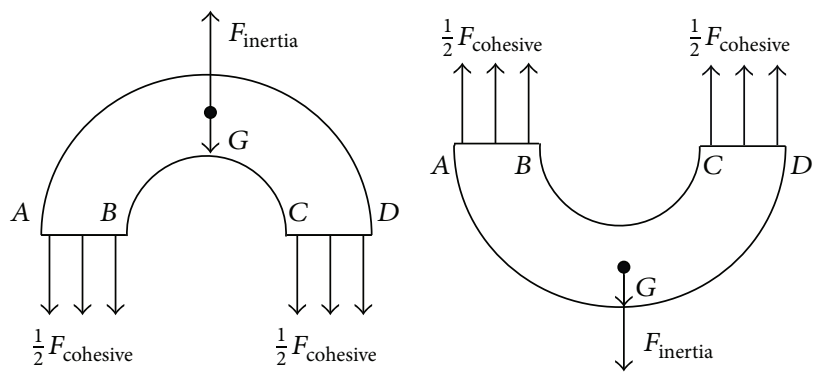

FIGURE 1: Free-body diagram of ice deposits.

\section{Modeling the Ice Detachment Process in FE Analysis}

2.1. Modified Ice Detachment Criterion. Field observations indicate that a thin liquid water film forms on the interface of ice and cable before natural ice shedding occurs [21], and the water film makes the adhesive force at the interface vanish. In that case, the only force that keeps the ice deposits on the cable is the cohesive force within the ice, and the ice will be shed off the cable if the resultant force acting on the ice accretion is greater than its cohesive force. Considering the above, the ice detachment criterion proposed in [19] can be modified to consider the induced-ice-shedding phenomenon triggered by random initial natural ice shedding. The modified criterion can be stated as follows: the ice deposit remaining on the cable will be shed off during the vibration generated by the initial ice shedding, if the resultant of vertical inertia force and gravity acting on the ice deposit is greater than the cohesive force within the ice. The free body diagram of an idealized cylindrical ice accretion is shown in Figure 1. The ice deposit is assumed to be split into two parts along line A-B-C-D, as explained in [19].

Then, the ice detachment criterion can be described as

$$
F_{\text {inertia }} \pm G \geq F_{\text {cohesive }},
$$

where $G, F_{\text {inertia }}$, and $F_{\text {cohesive }}$ are gravity, inertia, and cohesive forces:

$$
\begin{aligned}
F_{\text {inertia }} & =\frac{\pi \rho_{\text {ice }} l a}{8}\left[D^{2}-D_{\text {cable }}{ }^{2}\right] \\
G & =\frac{\pi \rho_{\text {icce }} l g}{8}\left[D^{2}-D_{\text {cable }}{ }^{2}\right] \\
F_{\text {cohesive }} & =\left(D-D_{\text {cable }}\right) l \cdot \tau_{\text {cohesive }},
\end{aligned}
$$

where $\rho_{\text {ice }}$ is the density of ice, $l$ is the length of the ice deposit, $a$ is the vertical acceleration acting on the ice, $D_{\text {cable }}$ is the diameter of cable, $D$ is the outer diameter of the ice profile, and $\tau_{\text {cohesive }}$ is the cohesive strength.

\subsection{Implementation of Ice Detachment Criterion in FE Anal-} $y$ sis. In FE simulation, the shedding of ice is simulated by setting the mass and stiffness components of the detached ice element in the global matrices to be "zero" [8, 16-19], when the ice detachment criterion (1) is satisfied. This process 
TABLE 1: Comparison of RIS (\%) obtained in tests and using different criteria for ice shedding.

\begin{tabular}{lccc}
\hline & \multicolumn{2}{c}{ Reduced-scale tests } & Real-scale test \\
& No. 1 & No. 2 & \\
\hline Experiment & 9 & 5 & 70 \\
Stress criterion & 100 & 100 & 100 \\
Strain criterion & 100 & 42 & 63.4 \\
Detachment criterion & 9.3 & 4 & 68.4 \\
\hline
\end{tabular}

can be done by setting the ice detachment criterion as the ice element "DEATH" condition in a user-defined element rupture subroutine, which fully interacts with the main ADINA program [19]. The forces are not obtained directly in the subroutine, while the acceleration is accessible. So the acceleration needed to shed off the ice can be determined by (5) from (1) to (4), and (5) is used in the subroutine as the detachment criterion instead of (1):

$$
a \geq \frac{8\left(D-D_{\text {cable }}\right) \tau_{\text {cohesive }}}{\pi \rho_{\text {ice }}\left(D^{2}-D_{\text {cable }}^{2}\right)} \pm g,
$$

where "+" is for the upper part of the ice deposit and "-" is for its lower part. It should be noted that the acceleration is independent of length, for $l$ is eliminated during the derivation.

Then, the implementation of the criterion in FE analysis proceeds as follows [19]: (1) at the beginning of each time step, the FE model of the iced transmission line system following initial random ice shedding is solved to get the acceleration vector at each integration point of the ice elements; (2) then, the user-defined subroutine is called by the main program to check if condition (5) is achieved for the considered ice element; if yes, the element is set to "DEATH" and the global mass and stiffness matrices of the system are updated; otherwise, the analysis continues until every ice element in this time step is checked and the global matrices are updated properly; (3) the above two steps are repeated until all the time steps of the prescribed solution time are completed.

2.3. Validation of the Modeling Method. No natural ice shedding test results with adequate details are reported in open literature that could be used to validate the proposed modeling method directly. However, in a similar study by the authors [19], the original ice detachment criterion and the implementation of the criterion in ADINA had been fully validated by both reduced-scale and real-scale physical tests. Table 1 shows the comparison of ratios of ice shedding (RIS, i.e., the ratio of "detached" ice amount to the ice amount before deicing) observed in the experiments and those obtained with different numerical methods. These results show that the ice detachment criterion is superior to other methods to predict the amount of ice shedding.

Since only the expression of acceleration (adhesive force is not considered in the present study while being included in [19]) and the source of initial shocks (resulting from initial natural ice shedding in the present study, while resulting from external mechanical impulse in [19]) in the present study are different from those in [19], which means that no essential difference exists between the two, it is reasonable to use a similar modeling method to investigate the dynamic response of iced transmission line following natural ice shedding.

\section{Equilibrium Equations and Time-Varying Global Matrices}

The dynamic system of transmission lines following ice shedding is highly nonlinear mostly due to the large displacement kinematics of the cables [19]. Besides, the mass, stiffness, and damping are time varying, owing to the induced-iceshedding effect. The governing equations of motion can be expressed as (6) in incremental FE form [22]:

$$
\begin{aligned}
& { }^{t+\Delta t} M^{t+\Delta t} \ddot{U}^{(k)}+{ }^{t+\Delta t} C^{t+\Delta t} \dot{U}^{(k)} \\
& +\left({ }^{t+\Delta t} K_{\mathrm{L}}+{ }^{t+\Delta t} K_{\mathrm{NL}}\right) \Delta U^{(k)}={ }^{t+\Delta t} R-{ }^{t+\Delta t} F^{(k-1)},
\end{aligned}
$$

where ${ }^{t+\Delta t} \ddot{U}^{(k)},{ }^{t+\Delta t} \dot{U}^{(k)}$, and $\Delta U^{(k)}$ are vectors of accelerations, velocities, and incremental displacements obtained in iteration (k), respectively; ${ }^{t+\Delta t} M$ is the mass matrix, ${ }^{t+\Delta t} C$ is the damping matrix, ${ }^{t+\Delta t} K_{\mathrm{L}}$ is the linear strain incremental stiffness matrix, ${ }^{t+\Delta t} K_{\mathrm{NL}}$ is the nonlinear strain (geometric or initial stress) incremental stiffness matrix, ${ }^{t+\Delta t} R$ is the vector of external applied nodal point loads, ${ }^{t+\Delta t} F^{(k-1)}$ is the vector of the nodal point forces equivalent to the element stresses in the configuration corresponding to the displacements ${ }^{t+\Delta t} U^{(k-1)}$, and ${ }^{t+\Delta t} U^{(k)}={ }^{t+\Delta t} U^{(k-1)}+\Delta U^{(k)}$ are the vector of displacements in iteration $(k)$ [22].

As in previous studies [16-20], the cable is modeled by two-node prestressed truss elements with tension-only elastic material and with two translational degrees of freedom (DOFs) at each node; the ice accretion is simulated by twonode iso-beam elements, with plastic bilinear material and with two translational DOFs and a rotational DOF at each node. The cable element and ice element are parallel to each other and share the same end nodes [16-20] to form a "composite-like" iced-cable element, as shown in Figure 2(a). When the ice is shed off the cable, only the cable element is left, as in Figure 2(b), where $n$ and $n+1$ are the labels of element nodes.

The time-varying process of the global mass, stiffness, and damping matrices is illustrated in detail next.

3.1. Time-Varying Mass Matrices. Before ice shedding, the mass of the iced cable element is the summation of the masses of the cable and ice beam elements, as shown in (7) where the lumped mass assumption is used:

$$
\begin{aligned}
{ }_{e}^{t} M_{i} & ={ }_{e}^{t} M_{i-\text { beam }}+{ }_{e}^{t} M_{i-\text { truss }} \\
{ }^{t} M_{i} & =\left(\begin{array}{cccccc}
{ }^{t} m_{11} & 0 & 0 & 0 & 0 & 0 \\
0 & { }^{t} m_{22} & 0 & 0 & 0 & 0 \\
0 & 0 & 0 & 0 & 0 & 0 \\
0 & 0 & 0 & { }^{t} m_{44} & 0 & 0 \\
0 & 0 & 0 & 0 & { }^{t} m_{55} & 0 \\
0 & 0 & 0 & 0 & 0 & 0
\end{array}\right) .
\end{aligned}
$$




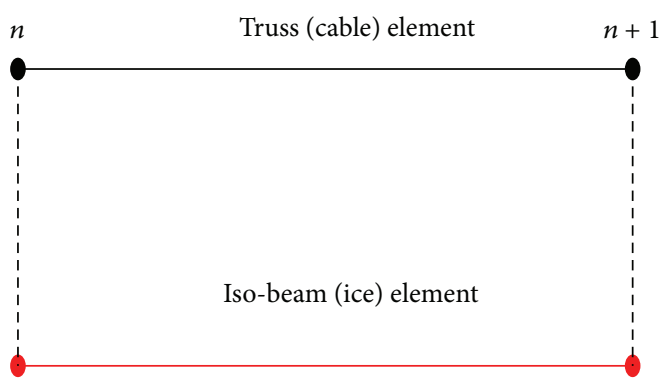

(a) Before ice shedding

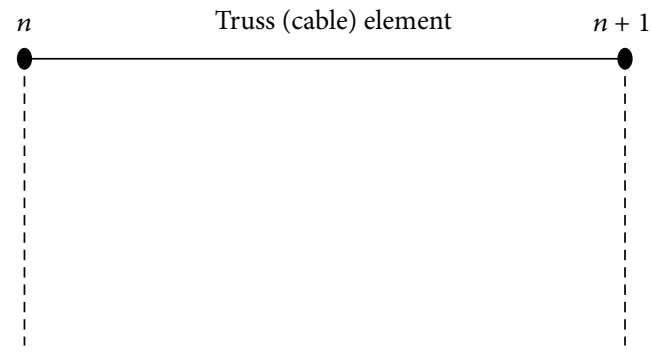

(b) After ice shedding

FIgURE 2: FE models before and after ice shedding.

The entries in the element mass matrix are

$$
{ }^{t} m_{i i}=\frac{l_{e}}{2}\left(\rho_{\text {ice }} A_{\text {ice }}+\rho_{\text {cable }} A_{\text {cable }}\right) \quad(i=1,2,4,5),
$$

where $l_{e}$ is the length of the element, $A_{\text {ice }}, A_{\text {cable }}$ are the area of ice and cable, and $\rho_{\text {cable }}$ is the density of cable.

When the ice is shed off at time step $t+\Delta t$, the components of ice in the mass matrix are set to be "zero," and the mass matrix can be expressed as (9) as follows:

$$
\begin{aligned}
& { }_{{ }^{t+\Delta t} M_{i}={ }^{t+\Delta t}{ }_{e} M_{i-\text { truss }}}{ }^{t+\Delta t} M_{i} \\
& =\left(\begin{array}{cccccc}
{ }^{t+\Delta t} m_{11} & 0 & 0 & 0 & 0 & 0 \\
0 & { }^{t+\Delta t} m_{22} & 0 & 0 & 0 & 0 \\
0 & 0 & 0 & 0 & 0 & 0 \\
0 & 0 & 0 & { }^{t+\Delta t} m_{44} & 0 & 0 \\
0 & 0 & 0 & 0 & { }^{t+\Delta t} m_{55} & 0 \\
0 & 0 & 0 & 0 & 0 & 0
\end{array}\right)
\end{aligned}
$$

with the entries rewritten as

$$
{ }^{t+\Delta t} m_{i i}=\frac{l_{e} \rho_{\text {cable }} A_{\text {cable }}}{2} \quad(i=1,2,4,5) .
$$

The components of the global mass matrix corresponding to all the detached ice elements during time step $t+\Delta t$ are updated before the solving of the next time step.
3.2. Time-Varying Stiffness Matrices. When the induced iceshedding effect is considered, the change in system stiffness during vibration is resulting not only from the material nonlinearity (if such nonlinearities occur) but also from the detachment of ice deposits.

The change in the stiffness matrix $\left({ }^{t+\Delta t} K_{\mathrm{L}}\right.$ in (6)) due to ice shedding is performed in the same way as for the mass matrix. The element stiffness matrix before ice shedding can be written as

$$
\begin{aligned}
{ }_{e}^{t} K_{i}^{(k)} & ={ }_{e}^{t} K_{i \text {-beam }}^{(k)}+{ }_{e}^{t} K_{i \text {-truss }}^{(k)} \\
{ }_{e}^{t} K_{i}^{(k)} & =\left(\begin{array}{cccccc}
k_{11} & 0 & 0 & k_{14} & 0 & 0 \\
0 & k_{22} & k_{23} & 0 & k_{25} & k_{26} \\
0 & k_{32} & k_{33} & 0 & k_{35} & k_{36} \\
k_{41} & 0 & 0 & k_{44} & 0 & 0 \\
0 & k_{52} & k_{53} & 0 & k_{55} & k_{56} \\
0 & k_{62} & k_{63} & 0 & k_{65} & k_{66}
\end{array}\right)
\end{aligned}
$$

with the components expressed as follows:

$$
\begin{aligned}
& k_{11}=k_{44}=\frac{\left(E_{\text {ice }}^{(k)} A_{\text {ice }}+E_{\text {cable }}^{(k)} A_{\text {cable }}\right)}{l_{e}} \\
& k_{22}=k_{55}=\frac{12 E_{\text {ice }}^{(k)} I_{\text {ice }}}{l_{e}^{3}} \\
& k_{14}=k_{41}=-\frac{\left(E_{\text {ice }}^{(k)} A_{\text {ice }}+E_{\text {cable }}^{(k)} A_{\text {cable }}\right)}{l_{e}} \\
& k_{23}=k_{32}=k_{26}=k_{62}=\frac{6 E_{\text {ice }}^{(k)} I_{\text {ice }}}{l_{e}^{2}} \\
& k_{33}=k_{66}=\frac{4 E_{\text {ice }}^{(k)} I_{\text {ice }}}{l_{e}} \\
& k_{25}=k_{52}=-\frac{12 E_{\text {ice }}^{(k)} I_{\text {ice }}}{l_{e}^{3}} \\
& k_{35}=k_{53}=k_{56}=k_{65}=-\frac{6 E_{\text {ice }}^{(k)} I_{\text {ice }}}{l_{e}^{2}} \\
& k_{36}=k_{63}=\frac{2 E_{\text {ice }}^{(k)} I_{\text {ice }}}{l_{e}},
\end{aligned}
$$

where $E_{\text {ice }}^{(k)}$ and $E_{\text {cable }}^{(k)}$ are Young's moduli of ice and cable, respectively. 
From time step $t+\Delta t$, when the ice is shed off, only the cable contributes to the system stiffness, and the element stiffness matrix can be expressed as

$$
\begin{aligned}
{ }^{t+\Delta t}{ }_{e} K_{i}^{(k)}={ }^{t+\Delta t}{ }_{e} K_{i-\text { truss }}^{(k)} & \\
{ }_{e}^{t+\Delta t} K_{i}^{(k)}= & \left(\begin{array}{cccccc}
k_{11} & 0 & 0 & k_{14} & 0 & 0 \\
0 & 0 & 0 & 0 & 0 & 0 \\
0 & 0 & 0 & 0 & 0 & 0 \\
k_{41} & 0 & 0 & k_{44} & 0 & 0 \\
0 & 0 & 0 & 0 & 0 & 0 \\
0 & 0 & 0 & 0 & 0 & 0
\end{array}\right)
\end{aligned}
$$

with the entries expressed as

$$
\begin{aligned}
& k_{11}=k_{44}=\frac{E_{\text {cable }}^{(k)} A_{\text {cable }}}{l_{e}} \\
& k_{14}=k_{41}=-\frac{E_{\text {cable }}^{(k)} A_{\text {cable }}}{l_{e}} .
\end{aligned}
$$

The updating of the stiffness matrix due to induced-iceshedding is performed before solving the next time step, by calling the user-defined subroutine, while the updating of the stiffness matrix due to material/geometric nonlinearities is performed automatically by the main ADINA program, using the full Newton method at every iteration step $[8,22]$.

3.3. Time-Varying Damping Matrices. In previous numerical studies, damping was modeled either by nonlinear spring/damper elements parallel to the cable elements and ice elements as in $[6,7,16-19]$ or by Rayleigh damping as in $[9,14,23]$. Since the Rayleigh damping model can consider explicitly the system mass and stiffness, it is used in the present study to check the differences between dynamic responses with and without considering the induced-iceshedding effect. As expressed in (15), the change of damping due to the detachment of ice during the vibration can be considered because the global mass and stiffness matrices are changing during the vibration. In previous studies, only the mass and stiffness of the cable were included in the Rayleigh damping calculation as in (16):

$$
\begin{aligned}
& { }^{t+\Delta t} C=\alpha^{t+\Delta t} M+\beta^{t+\Delta t} K \\
& { }^{t+\Delta t} C=\alpha^{t+\Delta t} M_{\text {truss }}+\beta^{t+\Delta t} K_{\text {truss }}
\end{aligned}
$$

where ${ }^{t+\Delta t} M,{ }^{t+\Delta t} K$ are the system mass and stiffness matrices including the components of both ice and cable elements, respectively; ${ }^{t+\Delta t} M_{\text {truss }},{ }^{t+\Delta t} K_{\text {truss }}$ are the system mass and stiffness matrices including the components of cable elements only. The damping matrix in (15) is updated at the same time when the global mass matrix and stiffness matrix are updated, as indicated in Sections 3.1 and 3.2. The damping matrix in (16) is updated according to the nonlinear material property of cable only.

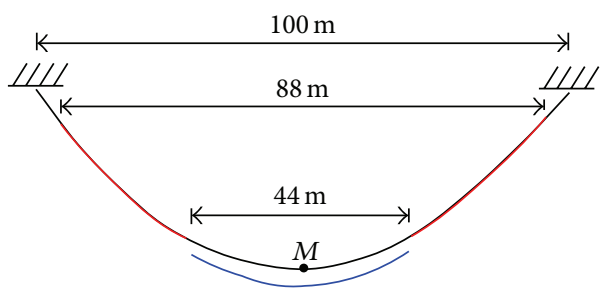

FIgURE 3: Schematic of the ice shedding line.

TABle 2: Parameters of GW used in the test.

\begin{tabular}{lc}
\hline Diameter $(\mathrm{mm})$ & 12.7 \\
Unit mass $(\mathrm{kg} / \mathrm{m})$ & 0.759 \\
Section area $\left(\mathrm{mm}^{2}\right)$ & 96.5 \\
Rated tensile strength $(\mathrm{kN})$ & 113.6 \\
Young's modulus $(\mathrm{GPa})$ & 172.4 \\
\hline
\end{tabular}

3.4. Solving of the System-Governing Equations. The Newmark- $\beta$ implicit integration method is used for equilibrium equations solving and the full Newton iteration method for stiffness updating [22]. When the ice sheds off during the interval $t+\Delta t$, the mass matrix is corrected (the mass of the shed ice element is removed) at time $t+\Delta t$, and the governing equations of motion (6) are solved iteratively.

\section{Case Study}

A single span transmission line section following natural ice shedding is chosen as a case study to demonstrate the differences between the FE model results with and without considering the induced-ice-shedding effect. The line section has a span length of $100 \mathrm{~m}$ (Figure 3).

The cable is an overhead ground wire (GW) with characteristics listed in Table 2. The ice thickness is $12.7 \mathrm{~mm}$, making the outer diameter of the iced cable be $38.1 \mathrm{~mm}$, that is, $D=38.1 \mathrm{~mm}$ in (5), and $88 \mathrm{~m}$ of the GW is covered by ice (the $44 \mathrm{~m}$ central portion will be assumed to shed; see Figure 3). The ice has a density of $900 \mathrm{~kg} / \mathrm{m}^{3}$ and Young's modulus of $10 \mathrm{GPa}$ [16-20]. With satisfactory results obtained in a previous study, the same mesh size is used with 500 cable elements and 440 ice beam elements.

4.1. Influence of Time-Varying Mass and Stiffness. It is assumed that a total amount of $50 \%$ of the ice (i.e., $44 \mathrm{~m}$, the central portion in Figure 3) was shed off initially (i.e., the initial ice shedding) in an instant. Then, two different modeling methods are employed to study the following dynamic response of the line section.

The first method is the same as that used in previous studies $[6,7,9,11,12,14,15]$, where no ice failure criterion is considered so that no further ice deposit is shed off during the vibration generated by the initial ice shedding; the dynamic response only results from the $50 \%$ initial ice shedding. This modeling method is equivalent to the method proposed in present study when an unrealistic large critical acceleration value is used in the ice detachment criterion, to ensure that no ice can be shed off. 


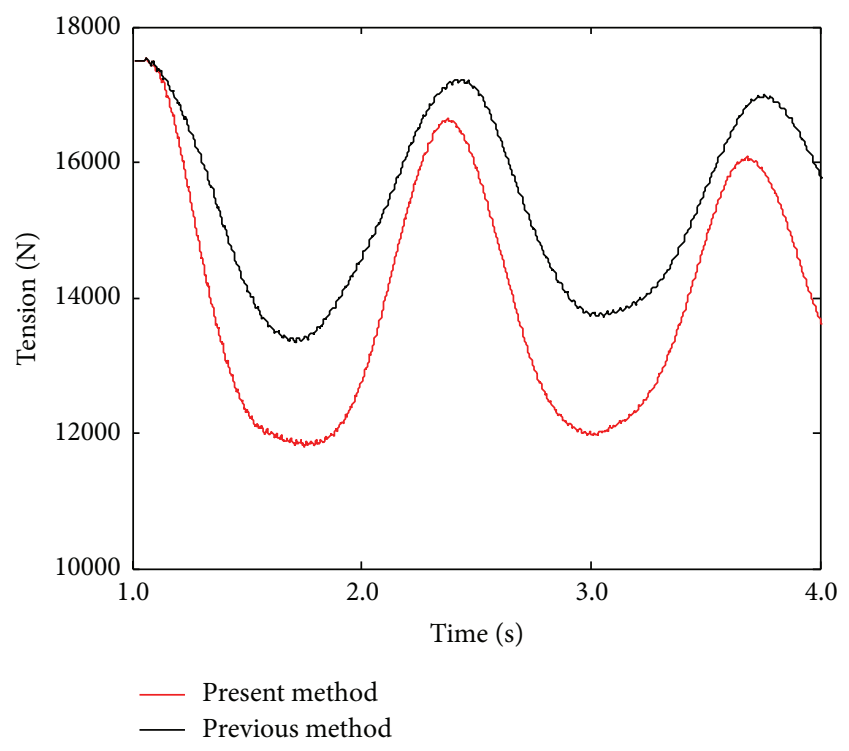

Figure 4: Tensions at the left end of the span.

The other method is that proposed in this paper, where the induced-ice-shedding effect is considered. Therefore, the ice detachment criterion described in Section 2 is used to check whether or not there is ice being shed off during the vibration and if yes, the global matrices are updated as discussed in Section 3. The induced-ice-shedding changes the characteristics of the system, making the dynamic response different from that obtained by the first modeling method.

To avoid confusion, the ice deposits are simulated by two element types. The initially detached ice deposits (the central part in Figure 3) are modeled by beam elements and the shedding process is simulated by prescribing a specific "DEATH" time (at the beginning of the solution) for the considered ice elements $[8,9]$. The remaining ice elements (the red part in Figure 3), which may be induced to shed off during the vibration, are simulated by iso-beam elements as described in Section 3. The detachment of these ice deposits is modeled by setting their element rupture criterion option in ADINA as "User Supplied," so that the user-defined element rupture subroutine will be called automatically to determine when the "DEATH" of these elements occurs $[19,20]$. The critical acceleration value in (5) is set to be $5 \mathrm{~m} / \mathrm{s}^{2}$, corresponding to the ice cohesive strength of $0.266 \mathrm{kPa}$ (calculated inversely by (5)), a reasonable and realistic value within the experimental range in open literature for dynamic strength tests of ice $[19,20]$.

The structural damping of the system is set to be equivalent to viscous damping of $2 \%$ critical as in $[6,7,9,11,13,15-$ $18,24]$, corresponding to $\alpha=0.136, \beta=0.003$ in (16) for the present model. The damping model presented in (15) is not used at this stage, since the main concern now is the influence of time-varying mass and stiffness caused by the inducedice-shedding. The Newmark- $\beta$ implicit integration method is used to solve the equilibrium equations, with $\delta=0.55$ and $\alpha=0.3$ [16-20], which also introduces numerical damping and helps to filter out spurious high frequency content of the response due to FE discretization.
TABLE 3: Comparison of simulation results.

\begin{tabular}{lcc}
\hline & $\begin{array}{c}\text { Min. residual } \\
\text { tension }(\mathrm{N})\end{array}$ & $\begin{array}{c}\text { Max. midpoint } \\
\text { displacement }(\mathrm{m})\end{array}$ \\
\hline Previous method & 13345 & 0.58 \\
Present method & 11801 & 1.02 \\
Difference & $11.6 \%$ & $75.9 \%$ \\
\hline
\end{tabular}

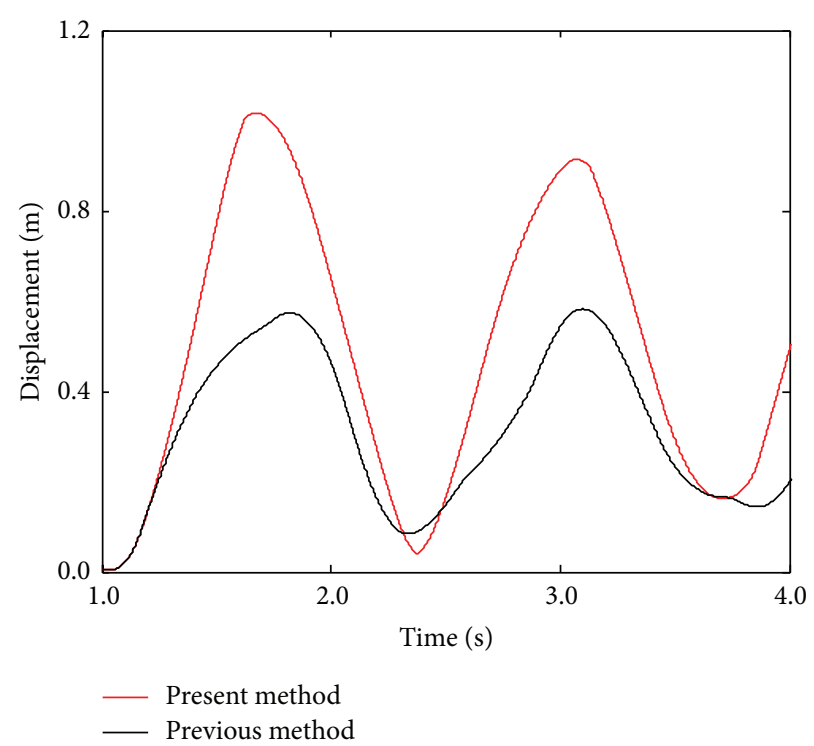

Figure 5: Displacements at the midpoint of the span.

The dynamic response of the system, in terms of axial tension of the cable at the left end of the span and cable vertical displacement at the midpoint of the span ( $M$ in Figure 3), is compared in Figures 4 and 5. The extreme values are listed and compared in Table 3.

Table 3 shows that when the induced-ice-shedding effect is considered, the minimum residual cable tension is $11.6 \%$ less and the maximum midpoint maximum displacement (cable jump) is $75.9 \%$ greater than the values obtained without considering subsequent induced ice shedding. The reason is that an additional $44 \mathrm{~m}$ of ice deposits $(22 \mathrm{~m}$ on each side of the central portion in Figure 3) was found to shed off during the vibration in FE simulation; more potential energy of the system was released due to the detachment of the ice and it was converted into kinetic energy. On the one hand, the minimum cable tension determines the maximum unbalanced load (the difference between the cable tensions of adjacent spans) acting on the towers, which is an important design consideration for the towers. So, the previous method that ignored subsequent ice shedding underestimates the maximum unbalanced loads and the threats of ice shedding. On the other hand, the large amplitude of cable vertical displacement may lead to flashovers due to insufficient electrical clearance between phase conductors, conductors to GWs, and conductors to ground, and it is seen that the previous method underestimates the maximum cable jump height.

Therefore, in conclusion, the previous method that ignored induced-ice-shedding underestimates the adverse 


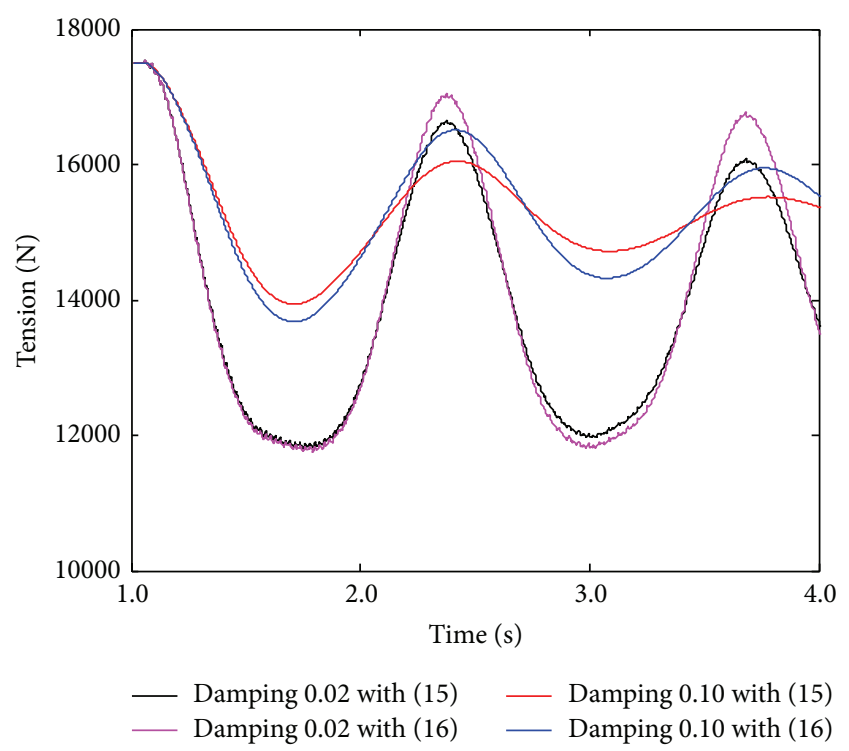

FIgURE 6: Comparison of cable tensions obtained with different damping models.

effects of natural ice shedding on the line. The authors therefore recommend that the more complete method proposed in this study should be used in numerical simulations to ensure the mechanical security of tower-line systems.

Besides, the authors have carried out discrete Fourier transformation analysis of the time histories in Figures 4 and 5 and obtained a dominant frequency around $0.75 \mathrm{~Hz}$, which lies in the interval between the natural frequencies of the first transverse vibration mode of the line section with bare GW $(0.91 \mathrm{~Hz})$ and fully iced GW $(0.72 \mathrm{~Hz})$. This further validates the proposed method, for the mass and stiffness of the transient dynamic system are in between those with bare GW and fully iced GW.

4.2. Influence of Damping Models. In previous studies [6, 7, $9,11,13,15-18,24]$, the $2 \%$ critical of viscous damping was often used for bare cable system and $10 \%$ critical for fullyiced cable system, and the latter corresponding to $\alpha=0.681$, $\beta=0.014$ in (15) and (16) for present iced GW model. To study the influence of different damping models and damping ratios, dynamic responses of the considered system are solved and compared in Figures 6 and 7 with four damping models, by combination of the expressions in (15) and (16) along with the two damping ratios.

Figures 6 and 7 indicate that the damping ratio has much more significant influence on the dynamic response of the system than the way of damping calculation has. The minimum residual tensions obtained with a damping ratio of $10 \%$ are greater than those with damping ratio of $2 \%$, by a proportion of $18.1 \%$ (damping calculated by (15)) and $16.4 \%$ (damping calculated by (16)), respectively. The maximum midpoint displacements are less than those obtained with damping ratio of $2 \%$, by a proportion of $52.9 \%$ (damping calculated by (15)) and 50.5\% (damping calculated by (16)), respectively. The reason for the significant difference is that

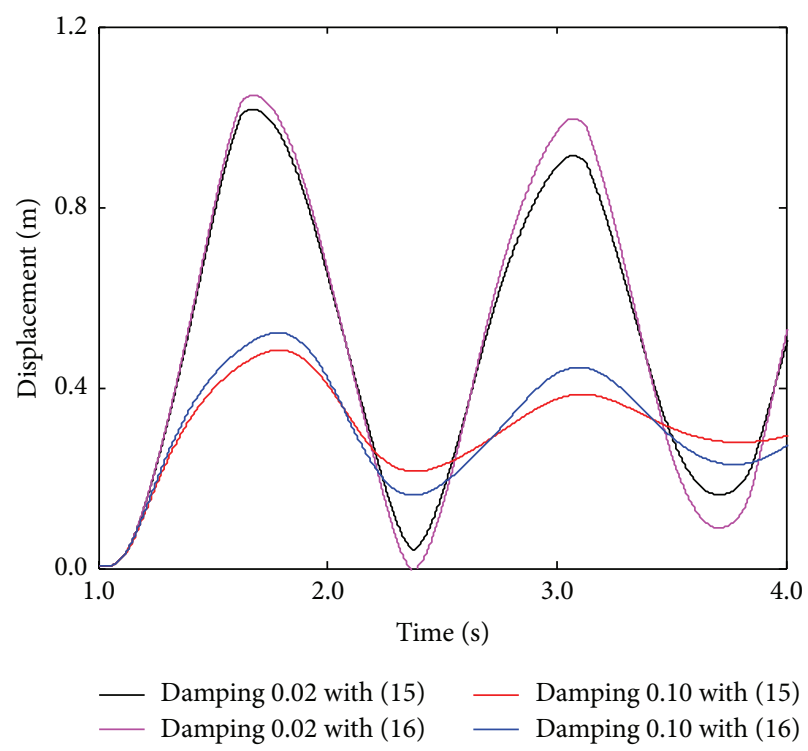

Figure 7: Comparison of midpoint displacements obtained with different damping models.

no induced-ice-shedding occurs when the large damping ratio is used, since a larger proportion of the vibration energy generated by the initial ice shedding is damped in such case.

The vibration amplitudes of the system obtained with damping model in (15) are a little less than those with damping model in (16) when the same damping ratio is used, with a difference ratio of less than $7.7 \%$ for both cable tensions and midpoint displacements. This implies that the inducedice-shedding effect has little influence on the system damping characteristics when the damping ratio is constant. Therefore, the induced-ice-shedding effect mainly affects the mass and stiffness properties of the system and then affects the dynamic response of system.

\section{Conclusions}

The induced-ice-shedding effect is considered in the dynamic response of transmission line system following nature ice shedding in the paper. The effect concerned is successfully simulated in FE analysis, by introducing a modified ice detachment criterion into the user-defined element rupture subroutine. The time-varying characteristics of the system mass, stiffness, and damping, due to that effect, are demonstrated.

Case study of a line section following natural ice shedding shows that the changes of the system mass and stiffness, resulting from the induced-ice-shedding effect, and the change of damping ratio have significant influence on the dynamic response of the system. However, the time-varying characteristic of damping, due to induced-ice shedding effect, has little influence. Most importantly, it is found that the previous modeling methods, without considering the induced-ice-shedding effect, largely underestimate the adverse impacts of natural ice shedding on transmission line system in the studied case. Thus, the method proposed in the 
present study should be used in the design and evaluation of transmission lines in cold regions in the future, to ensure the mechanical security of towers-lines system.

To the best of our knowledge, this is the first attempt that the realistic induced-ice-shedding effect is explicitly taken into account in the dynamic response analysis of transmission line system following natural ice shedding. Dynamic response of transmission line system impacted by other types of shock loads, such as those due to conductor breakage, insulator rupture, and clamp slippage, can also be investigated using the same method of this paper. With the method proposed in the present study, future work on the towers-cables interaction effect of multispan lines and on the bundle conductors following natural ice shedding may further improve the design and evaluation of transmission lines in practice.

\section{Conflict of Interests}

The authors declare that there is no conflict of interests regarding the publication of this paper.

\section{Acknowledgments}

The financial supports from the China Scholarship Council (201206370008), the National Science Foundation of China (51205128), the Beijing Natural Science Fund (8152027), and the Natural Sciences and Engineering Research Council of Canada are acknowledged.

\section{References}

[1] W. T. van Horssen, O. V. Pischanskyy, and J. L. A. Dubbeldam, "On the forced vibrations of an oscillator with a periodically time-varying mass," Journal of Sound and Vibration, vol. 329, no. 6, pp. 721-732, 2010.

[2] W. T. van Horssen and O. V. Pischanskyy, "On the stability properties of a damped oscillator with a periodically timevarying mass," Journal of Sound and Vibration, vol. 330, no. 13, pp. 3257-3269, 2011.

[3] C. Zhou, Y. Liu, and X. Rui, "Mechanism and characteristic of rain-induced vibration on high-voltage transmission line," Journal of Mechanical Science and Technology, vol. 26, no. 8, pp. 2505-2510, 2012.

[4] C. Zhou and Y. Liu, "Analytical model of high-voltage transmission line subjected to the downburst wind with rainfall," Advances in Mechanical Engineering, vol. 7, no. 3, pp. 1-13, 2015.

[5] V. T. Morgan and D. A. Swift, "Jump height of overhead-line conductors after the sudden release of ice loads," Proceedings of the Institution of Electrical Engineers, vol. 111, no. 10, pp. 17361746, 1964.

[6] A. Jamaleddine, G. McClure, J. Rousselet, and R. Beauchemin, "Simulation of ice-shedding on electrical transmission lines using ADINA," Computers and Structures, vol. 47, no. 4-5, pp. 523-536, 1993.

[7] M. R. Fekr and G. McClure, "Numerical modelling of the dynamic response of ice-shedding on electrical transmission lines," Atmospheric Research, vol. 46, no. 1-2, pp. 1-11, 1998.

[8] ADINA R-D Inc, ADINA Theory and Modeling Guide, ADINA R-D Inc, Watertown, Mass, USA, 2013.
[9] L. E. Kollár, M. Farzaneh, and P. Van Dyke, "Modeling ice shedding propagation on transmission lines with or without interphase spacers," IEEE Transactions on Power Delivery, vol. 28, no. 1, pp. 261-267, 2013.

[10] P. Van Dyke and A. Laneville, "Simulated ice shedding on a fullscale test line," in Proceedings of the 8th International Symposium on Cable Dynamics, Paris, France, 2009.

[11] L. E. Kollár and M. Farzaneh, "Vibration of bundled conductors following ice shedding," IEEE Transactions on Power Delivery, vol. 23, no. 2, pp. 1097-1104, 2008.

[12] L. E. Kollar and M. Farzaneh, "Modeling sudden ice shedding from conductor bundles," IEEE Transactions on Power Delivery, vol. 28, no. 2, pp. 604-611, 2013.

[13] X. Meng, L. Hou, L. Wang et al., "Oscillation of conductors following ice-shedding on UHV transmission lines," Mechanical Systems and Signal Processing, vol. 30, pp. 393-406, 2012.

[14] B. Yan, K. Q. Chen, Y. M. Guo, M. Liang, and Q. Yuan, "Numerical simulation study on jump height of iced transmission lines after ice shedding," IEEE Transactions on Power Delivery, vol. 28, no. 1, pp. 216-225, 2013.

[15] F. Yang, J. Yang, and H. Zhang, "Analyzing loads from ice shedding conductors for UHV transmission towers in heavy icing areas," Journal of Cold Regions Engineering, vol. 28, no. 3, Article ID 04014004, 2014.

[16] T. Kálmán, M. Farzaneh, and G. McClure, "Numerical analysis of the dynamic effects of shock-load-induced ice shedding on overhead ground wires," Computers \& Structures, vol. 85, no. 78, pp. 375-384, 2007.

[17] F. Mirshafiei, G. McClure, T. Kalman, and M. Farzaneh, "Improved ice shedding modelling of iced cables: a comparison with experimental data," in Proceedings of the Annual Conference of Canadian Society for Civil Engineering, pp. 978-987, Manitoba, Canada, 2010.

[18] F. Mirshafiei, G. McClure, and M. Farzaneh, "Modelling the dynamic response of iced transmission lines subjected to cable rupture and ice shedding," IEEE Transactions on Power Delivery, vol. 28, no. 2, pp. 948-954, 2013.

[19] K. Ji, X. Rui, L. Li, A. Leblond, and G. McClure, "A novel ice-shedding model for overhead power line conductors with the consideration of adhesive/cohesive forces," Computers \& Structures, vol. 157, pp. 153-164, 2015.

[20] G. McClure, K. Ji, and X. Rui, "An integrated ice shedding model of electric transmission lines with consideration of ice adhesive/ cohesive failure," in Preceeding of the 9th International Conference on Structural Dynamics, pp. 3731-3736, Porto, Portugal, 2014.

[21] J.-L. Laforte, M.-A. Allaire, and D. Gagnon, "Ice shedding of $200 \mathrm{~m}$-long artificially iced overhead cables at an outdoor test site," in Proceedings of the 11th International Workshop on Atmospheric Icing of Structures, Montréal, Canada, June 2005.

[22] K. J. Bathe, Finite Element Procedures, Prentice Hall, Upper Saddle River, NJ, USA, 2006.

[23] N. Barbieri, O. H. de Souza Júnior, and R. Barbieri, "Dynamical analysis of transmission line cables. Part 2-damping estimation," Mechanical Systems and Signal Processing, vol. 18, no. 3, pp. 671-681, 2004.

[24] G. McClure and M. Lapointe, "Modeling the structural dynamic response of overhead transmission lines," Computers \& Structures, vol. 81, no. 8-11, pp. 825-834, 2003. 

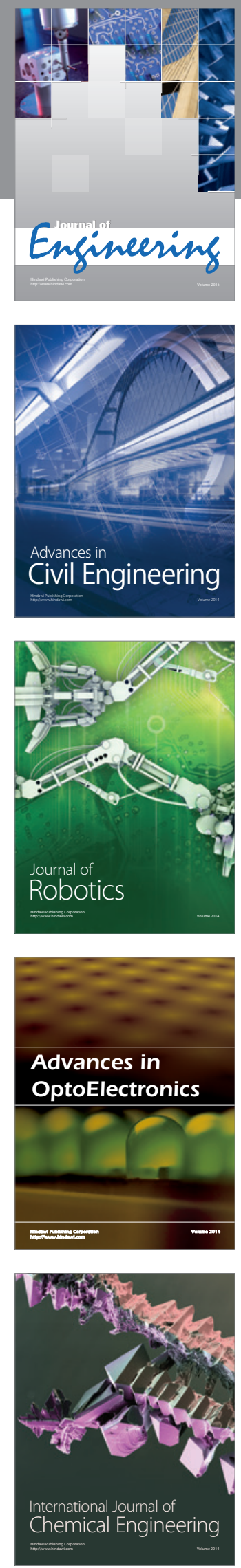

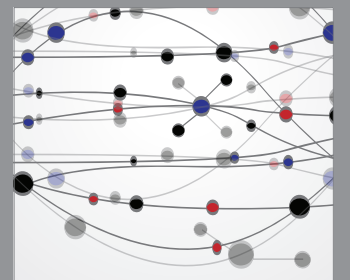

The Scientific World Journal
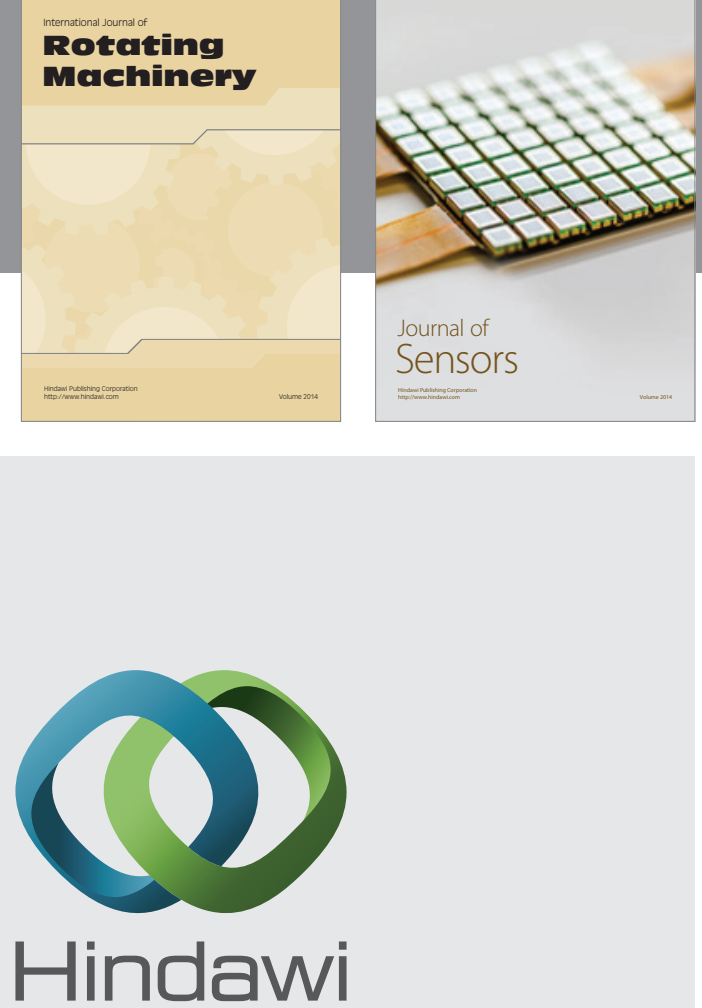

Submit your manuscripts at http://www.hindawi.com
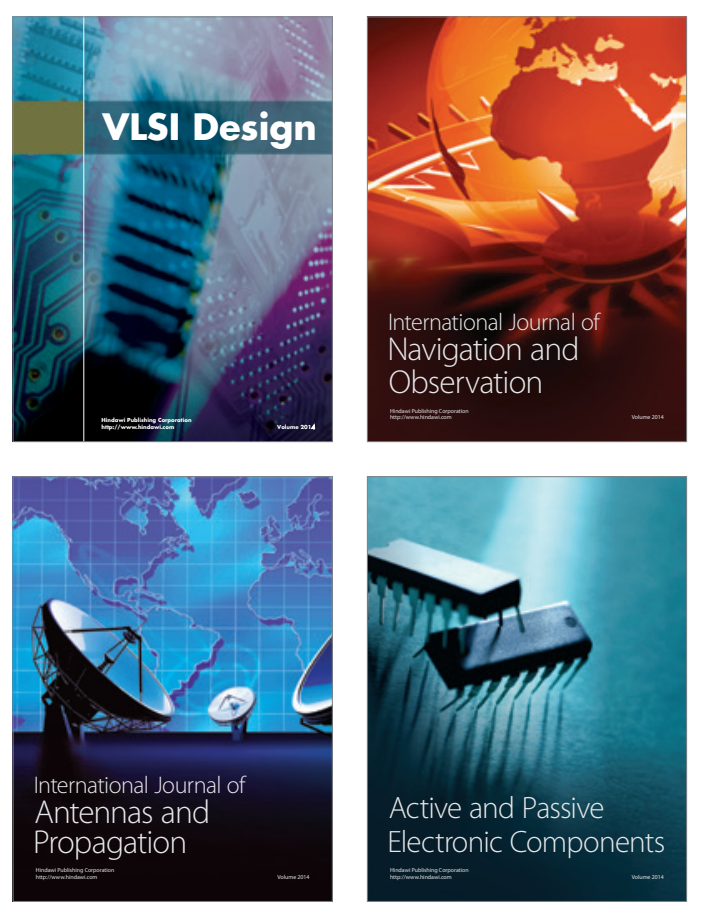
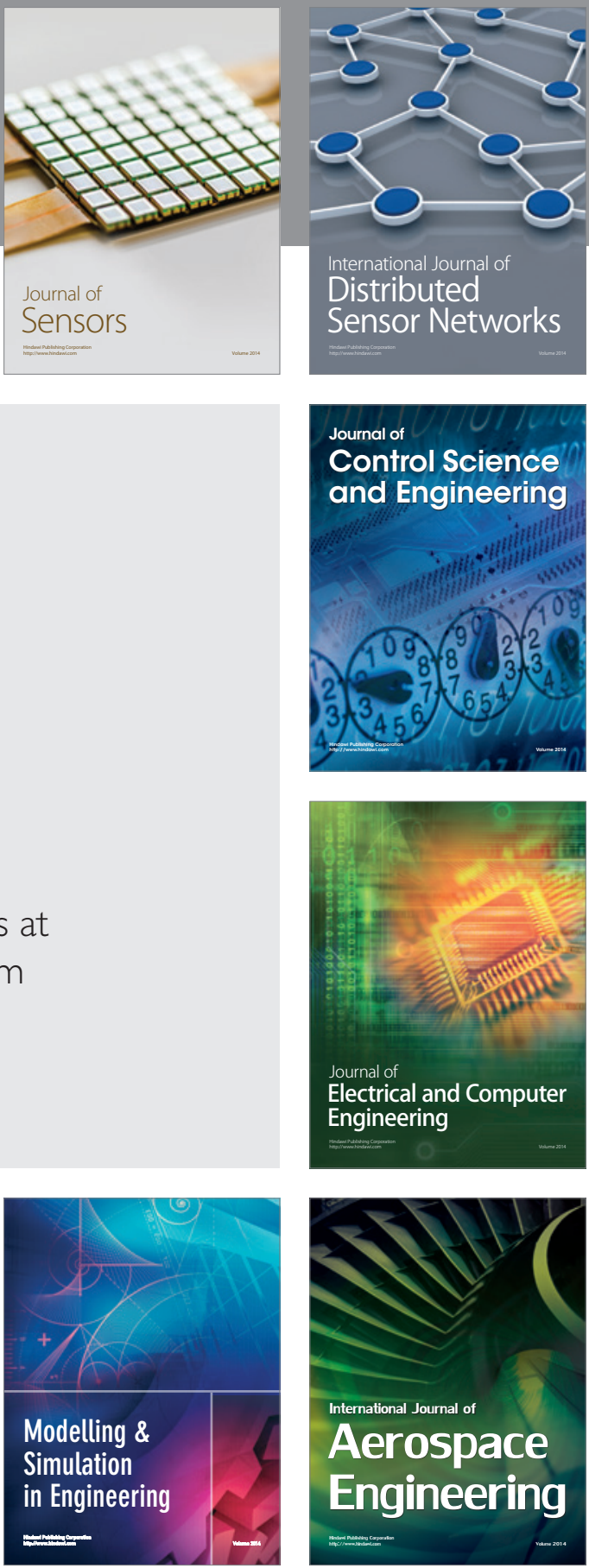

Journal of

Control Science

and Engineering
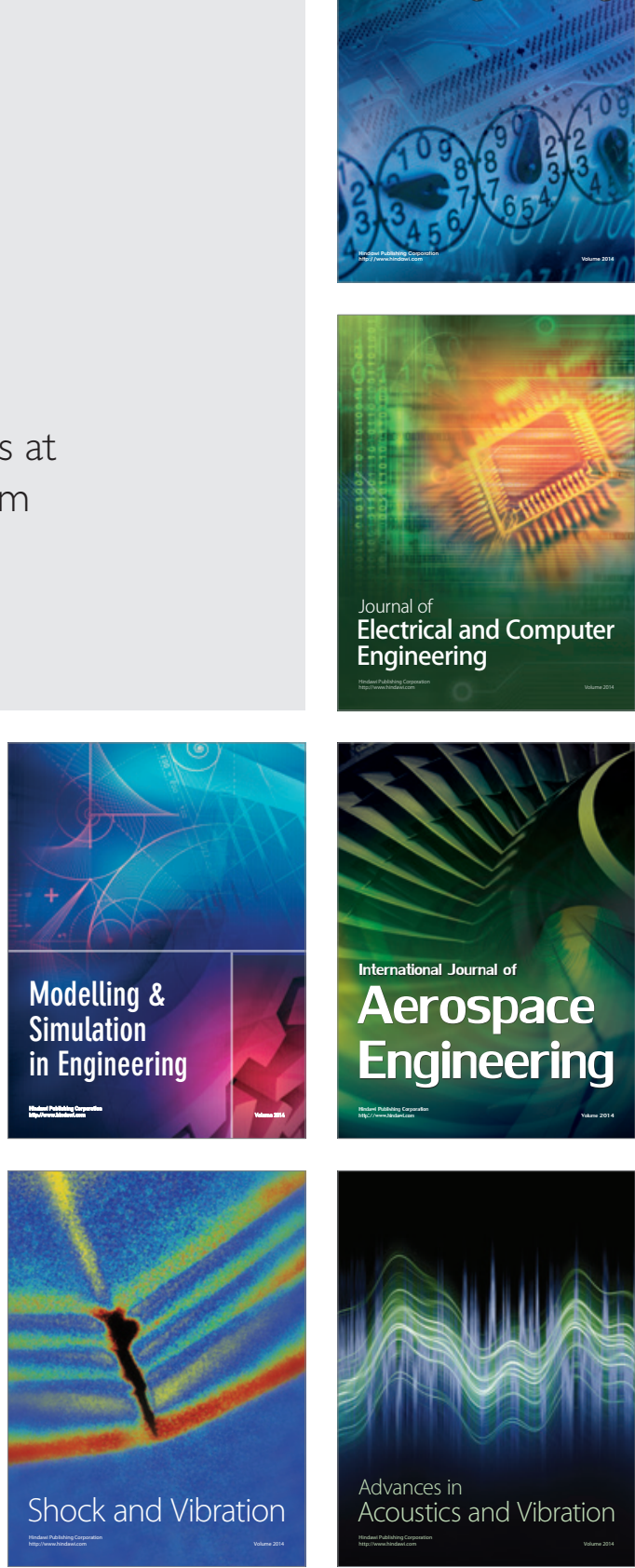